\title{
I EQUITY MARKET ANOMALIES AND BEHAVIOURAL FINANCE
}

\author{
Dr. Chabi Gupta \\ E-Mail Id: chabigupta@ yahoo.com \\ Professor, Galgotias University, Greater Noida, Uttar Pradesh (India)
}

\begin{abstract}
Behavioural finance theories explain "why" individuals exhibit behaviours that do not maximize expected utility. Behavioural finance highlights inefficiencies, such as under- or over-reactions to information, as causes of market trends and, in extreme cases, of bubbles and crashes. Such reactions have been attributed to limited investor attention, overconfidence, over optimis m, mimicry (herding instinct) and noise trading. Technical analysts consider behavioural finance to be behavioural economics' "academic cousin" and the theoretical basis for technical analysis.

This research work explores how anomalies in equity markets exist and there have been various discussions and arguments on this topic. It also researches the effect of these anomalies in the working of the equity stock markets in Indian context. This research expands on the research work of Shefrin [2000], who concluded through his research that recent stock market price changes exert a strong influence on risk tolerance attitudes and behaviours.
\end{abstract}

\section{INTRODUCTION}

The Efficient market hypothesis was developed by Professor Eugene Fama who argued that stocks always trade at their fair value, making it impossible for investors to either purchase undervalued stocks or sell stocks for inflated prices. As such, it should be impossible to outperform the overall market through expert stock selection or market timing, and that the only way an investor can possibly obtain higher returns is by chance or by purchasing riskier investments. His 2012 study with Kenneth French confirmed this view, showing that the distribution of abnormal returns of US mutual funds is very similar to what would be expected if no fund managers had any skill—a necessary condition for the EMH to hold.

There are three variants of the hypothesis: "weak", "semi-strong", and "strong" form. The weak form of the EMH claims that prices on traded assets (e.g., stocks, bonds, or property) already reflect all past publicly available information. The semi-strong form of the EMH claims both that prices reflect all publicly available information and that prices instantly change to reflect new public information. The strong form of the EMH additionally claims that prices instantly reflect even hidden "insider" information.

Critics have blamed the belief in rational markets for much of the late-2000s financial crisis. In response, proponents of the hypothesis have stated that market efficiency does not mean not having any uncertainty about the future, that market efficiency is a simplification of the world which may not always hold true, and that the market is practically efficient for investment purposes formost individuals.

In today's world investing in stocks and funds is made easy. Investors do not need any specific education or knowledge to purchase stocks. Current technology enhances fast trade between individual investors. The concept of investing is seen as trendy. Therefore, people tend to make illogical decisions not based on true knowledge or information of a certain investment object. These decisions are explained via several behavioural finance theories. The outcome of poor knowledge is that investors allow these theories to effect on their decision-making process, thus resulting in major losses. The behavioural models can effect on individuals' decision-making whether actual investments are conducted via professionals or not. The concept of investing is extensive as it can include all the aspects of purchasing items expected to gain more value in the future (art, antique, securities etc.). Therefore, it has decided to narrow down the subject to concentrate on stock trading and the impact of behavioural finance on individual portfolio investors.

The portfolio investor is a human being and to err is just natural. Extreme volatility has plagued financial markets worldwide since the 2008 Global Crisis. Investor sentiment has been one of the key determinants of market movements. In this context, studying the role played by emotions like fear, greed and anticipation, in shaping up investment decisions seemed important. Traditional finance assumes investors always behave rationally and they can process new information quickly and accurately, whereas the evolving field of behavioural finance assumes that investors suffer from cognitive and emotional biases which may lead to irrational and unexplained financial decision making. All too many investors are completely unaware of the mental pitfalls that await them. Even once they are aware of their cognitive biases, it must also be recognized that knowledge does not equal behaviour. Huge amount of information is readily available and it is upon the investor to differentiate and select.

Much of the economic and financial theories presume that individuals act rationally in the process of decision making, by considering all available information. But there is evidence to show repeated patterns of irrationality in the way humans arrive at decisions and choices when faced with uncertainty. Behavioural finance, a study of the market that draws on psychology, throws light on why people buy or sell stocks and why sometimes do not buy or sell at all. The most crucial challenge faced by the investor is in investment decisions. The profit made, or losses incurred by an investor can be attributed main ly to his decision-making abilities. The fact that even the 


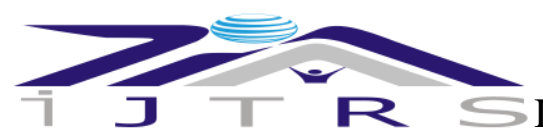

International Journal of Technical Research \& Science

most prominent and well-educated investors were affected by the collapse of the speculative bubble in the 2008 subprime crisis proved that something was fundamentally missing in the traditional models of rational market behaviour. In this study, the aim is to establish the existence of such fundamental issues, driven by various psychological biases, in the investment decision-making process. Behavioural economists firmly believe that psychological factors influence investment decisions. They argue that today's investment decisions demand a better understanding of individual investors' behavioural biases. However, many economists believe co mpletely in the application of traditional theories in the decision-making process and hence do not consider the concept of irrational behaviour. Behavioural finance therefore studies the influence of psychology on the behaviour of portfolio investors and their consequent reactions in stock market investing. It is an evolving field that studies how psychological factors affect decision making under uncertainty. In this context, it seems relevant to check whether the behavioural factors have an influence on the decision-making process of portfolio investors.

\section{COGNITIVE BIASES AND BEHAVIOURAL FINANCE}

The recent behavioural finance literature offers an alternative paradig $m$ in which individuals make systematic mistakes in the way that they process information. In this paper, we consider one of these biases, that of overconfidence. There are a number of reasons why we concentrate on this particular bias: first, it is perhaps the best established of these biases. Second, we view it as a bias that is likely to manifest itself in the sort of analysis that is necessary in security valuation. Finally, we argue that overconfidence is a trait that is likely to arise through evolutionary selection. We believe this last argument is extremely important. Behavioural biases that distort decisions with no offsetting benefits are likely to be eliminated by natural selection. Hence, we should be considerably more sceptical about the existence of biases that cannot be explained in this way.

Although many economists are sympathetic to the view that behavioural biases play a role in economic decisions, they generally believe that irrational investors have only a minor effect on prices. The standard argument is that, in competing to take advantage of the profit opportunities created by the trades of irrational investors, rational investors will push prices to a level where the profit opportunities virtually disappear. Thus, in the end, prices will be determined in the market "as if" all investors are rational.

Behavioural finance attempts to explain and increase understanding of the reasoning patterns of investors, including the emotional processes involved and the degree to which they influence the decision-making process. Essentially, behavioural finance attempts to explain the what, why, and how of finance and investing, from a human perspective. For instance, behavioural finance studies financial markets as well as provid ing explanations to many stock market anomalies (such as the January effect), speculative market bubbles (the recent retail Internet stock craze of 1999), and crashes (crash of 1929 and 1987). There has been considerable debate over the real definition and validity of behavioural finance since the field itself is still developing and refining itself. This evolutionary process continues to occur because many scholars have such a diverse and wide range of academic and professional specialties.

Lastly, behavioural finance studies the psychological and sociological factors that influence the financial decision-making process of individuals, groups, and entities as illustrated below.

Portfolio investors, to invest wisely and hoping for higher and consistent returns on their investment must overcome various cognitive biases that can cloud rational thinking. Some common mistakes made by investors are selling too soon while booking profits, holding too long while facing losses, buying overpriced stocks based on market sentiments and positive evaluation by all and sundry. The key, according to Parikh, for an investor so succeed is to be aware of the emotional indiscipline he has exhibited, and appropriately deal with it to avoid repetition. In the words of Warren Buffet,

"It is only when you combine sound intellect with emotional discipline that you get rational behaviour" Obara, C. A. (2015).

The presence of regularly occurring anomalies in conventional economic theory was a big contributor to the formation of behavioural finance. These so-called anomalies, and their continued existence, directly violate modern financial and economic theories, which assume rational and logical behaviour.

\section{ANOMALIES FOUND IN THE FINANCIAL LITERATURE}

\subsection{January Effect}

The January effect is named after the phenomenon in which the average monthly return for small firms is consistently higher in January than any other month of the year. This is at odds with the efficient market hypothesis, which predicts that stocks should move at a "random walk". However, a 1976 study by Michael S. Rozeff and William R. Kinney, called "Capital Market Seasonality: The Case of Stock Returns", found that from 1904-74 the average amount of January returns for small firms was around 3.5\%, whereas returns for all other months was closer to $0.5 \%$. This suggests that the monthly performance of s mall stocks follows a relatively consistent pattern, which is contrary to what is predicted by conventional financial theory. Therefore, some unconventional factor (other than the random-walk process) must be creating this regular pattern. One explanation is that the surge in January returns is a result of investors selling loser stocks in December to lock in tax losses, causing returns to bounce back up in January, when investors have less incentive to sell. 

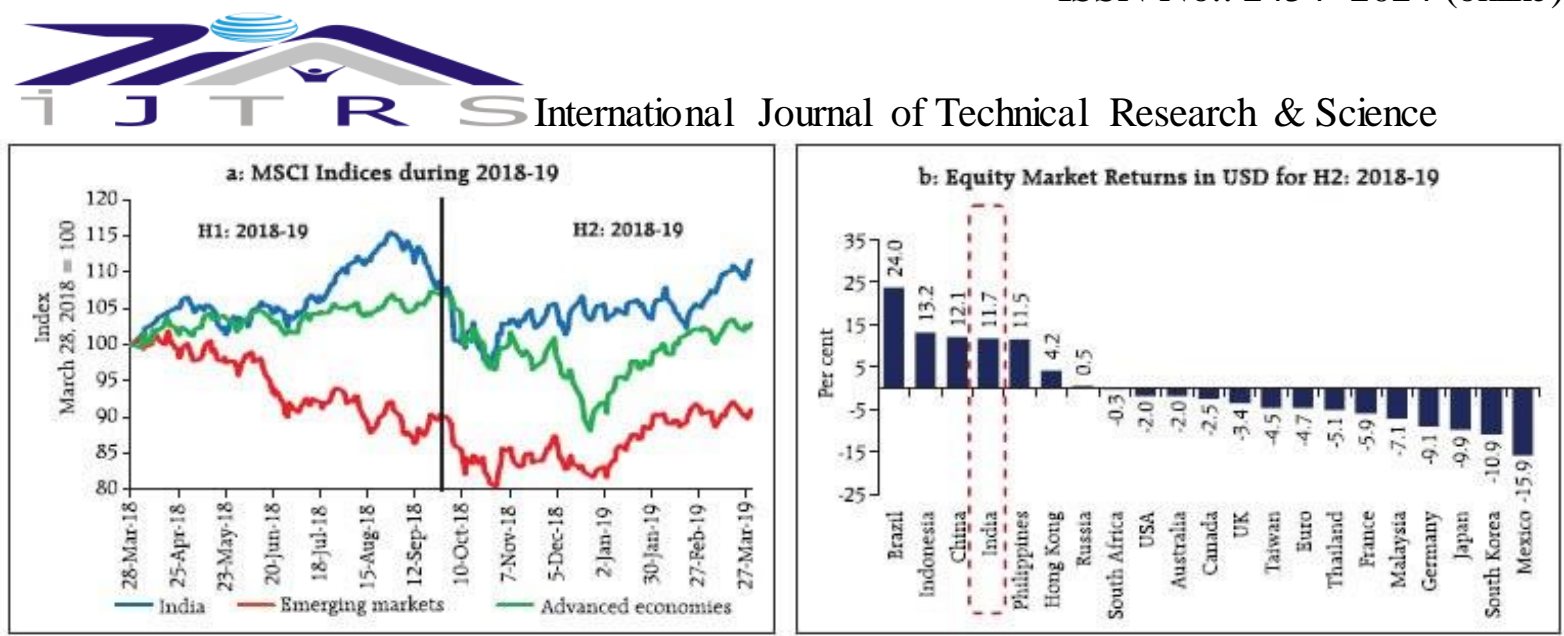

Fig. 3.1 Equity Market Indices and Returns

While the year-end tax selloff may explain some of the January effect, it does not account for the fact that the phenomenon still exists in places where capital gains taxes do not occur. This anomaly sets the stage for the line of thinking that conventional theories do not and cannot account for everything that happens in the real world.

\subsection{The Winner's Curse}

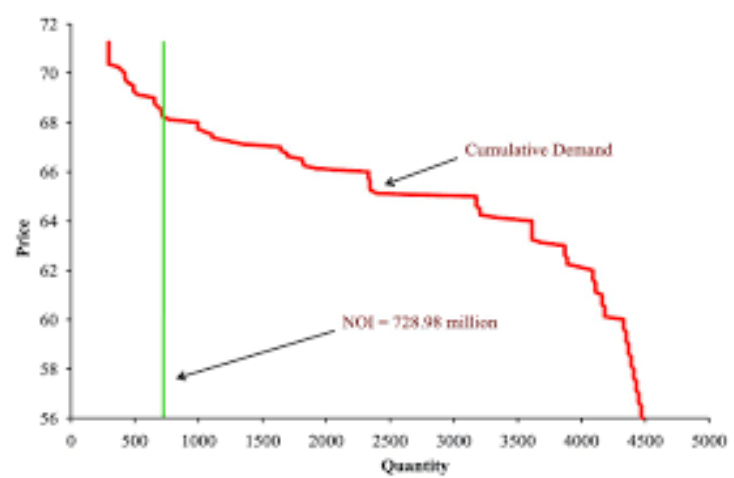

Fig. 3.2 Graph Winner' Curse

One assumption found in finance and economics is that investors and traders are rational enough to be aware of the true value of some asset and will bid or pay accordingly. However, anomalies such as the winner's curse - a tendency for the winning bid in an auction setting to exceed the intrinsic value of the item purchased - suggest that this is not the case. Rational-based theories assume that all participants involved in the bidding process will have access to all relevant information and will all come to the same valuation. Any differences in the pricing would suggest that some other factor not directly tied to the as set is affecting the bidding.

According to Richard Thaler's 1988 article on winner's curse, there are two primary factors that undermine the rational bidding process: the number of bidders and the aggressiveness of bidding. For example, the more bidders involved in the process means that one would have to bid more aggressively in order to dissuade others from bidding. Unfortunately, increasing the aggressiveness will also increase the likelihood that the winning bid will exceed the value of the asset. Consider the example of prospective homebuyers bidding for a house. It's possible that all the parties involved are rational and know the home's true value from studying recent sales of comparative homes in the area. However, variables irrelevant to the asset (aggressive bidding and the number of bidders) can cause valuation error, oftentimes driving up the sale price more than $25 \%$ above the home's true value. In this example, the curse aspect is twofold: not only has the winning bidder overpaid for the home, but now that buyer might have a difficult time securing financing.

\subsection{Equity Premium Puzzle}

An anomaly that has left academics in finance and economics scratching their heads is the equity premium puzzle. According to the capital asset pricing model (CAPM), investors that hold riskier financial assets should be compensated with higher rates of returns. Studies have shown that over a 70-year period, stocks yield average returns that exceed government bond returns by 6-7\%. Stock real returns are 10\%, whereas bond real returns are $3 \%$. However, academics believe that an equity premium of $6 \%$ is extremely large and would imply that stocks are considerably risky to hold over bonds. Conventional economic models have determined that this premium should be much lower. This lack of convergence between theoretical models and empirical results represents a stumbling block for academics to explain why the equity premium is so large. Behavioural finance's answer to the equity premium puzzle revolves around the tendency for people to have "myopic loss aversion", a situation in which investors - overly preoccupied by the negative effects of los ses in comparison to an equivalent a mount of gains - take a very short-term view on an investment. What happens is that investors are paying too much attention to the short-term volatility of their stock portfolios. While it is not uncommon for an average stock to fluctuate a few percentage points in a very short period of time, a myopic (i.e., short sighted) investor may not react too favourably to the downside changes. 


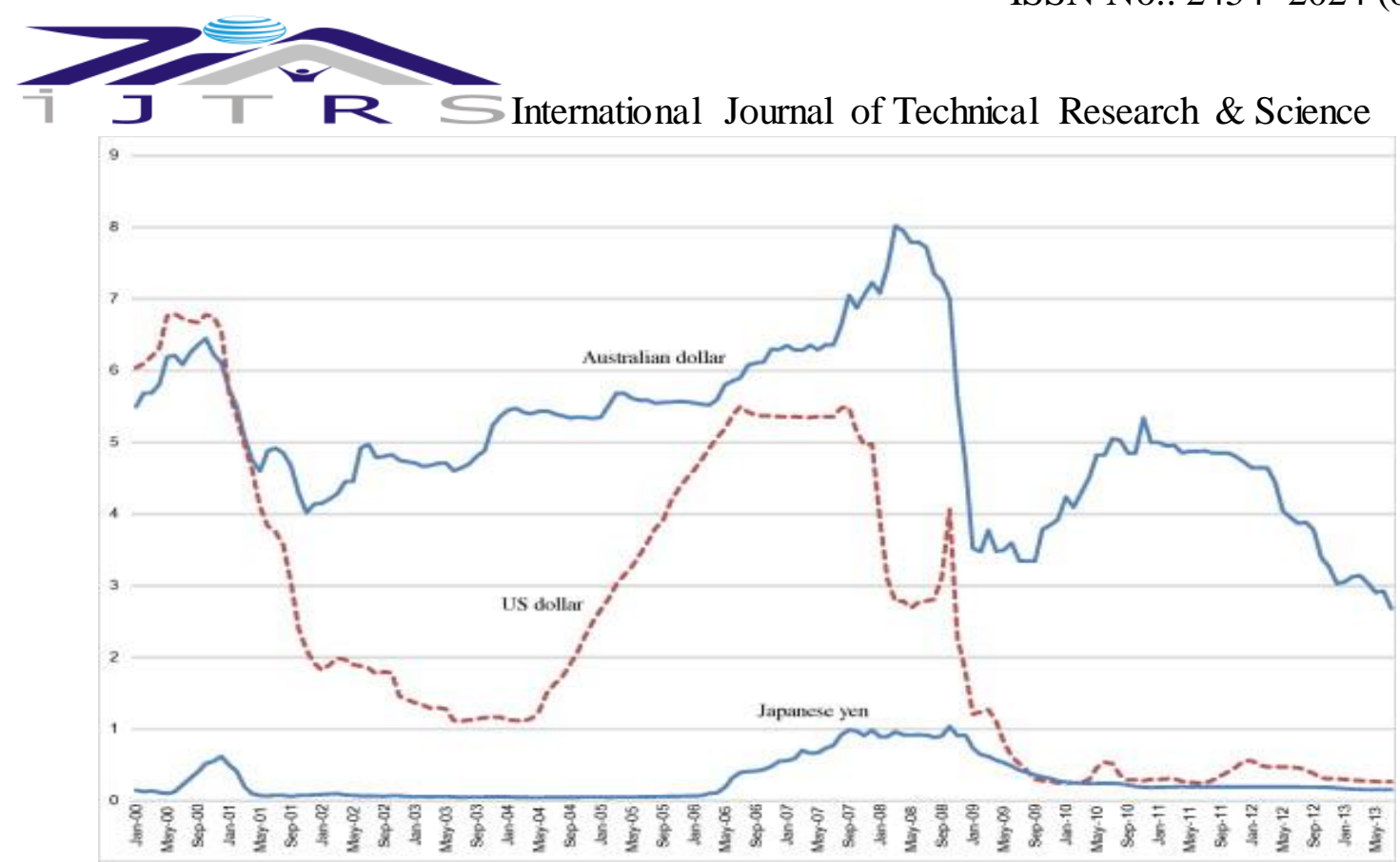

Fig. 3.3 Graph of the Equity Premium Puzzle

Therefore, it is believed that equities must yield a high-enough premium to compensate for the investor's considerable aversion to loss. Thus, the premium is seen as an incentive for market participants to invest in stocks instead of marginally safer government bonds. Conventional financial theory does not account for all situations that happen in the real world. This is not to say that conventional theory is not valuable, but rather that the addition of behavioural finance can further clarify how the financial markets work.

\section{CONCLUSION}

Up to 1970 s when the focus was on the study of the environ ment, the agents of the environment were set under some basic assumptions of standard finance theory. These assumptions were unrealistic and hence lead to erroneous conclusions. So, during 1980s when these assumptions were questioned the agents of the decisionmaking process and environment, i.e. the people became the subject matter of the study. This gave rise to a different branch of finance called behavioural finance, where in analysis is made about the role of psychological biases in decision making. This branch tried to relax the assumptions of standard finance theory and build the improved models of decision-making process. The emphasis has been on identifying portfolio anomalies that can be explained by various psychological traits in individuals or groups when it is possible to develop highly lucrative portfolio by exploiting the behavioural bias and to recognize that rational behaviour and profit maximization is not complete since it does not consider individual behavioural traits/biases of investors, analys ts or portfolio managers. Further, behavioural finance only acts as a supplement and not as a replacement to standard finance theory because it explains those phenomena that cannot be explain ed by the traditional finance theory. Theories of behavioural finance that are built on the models of standard finance can help the investors to understand their own behaviour and thus help them to improve upon their decision-making process keeping in view the models of traditional finance theories.

In sum, behavioural finance literature has grown by leaps and bounds in recent years. However, much work remains to be done in the field. The literature could shed specific light on which agents are biased and whose biases affect prices. There also is room to analyse the fast-growing field of market microstructure and Behavioural finance. For example, a central role played by financial markets is that of price discovery. What is the effect of cognitive biases of market makers on price formation? A start on the study of this subject is the paper by Corwin and Coughenour (2005) who argue that limited attention influences transaction costs. Specifically, it is shown that specialist attention gets diverted to the most active stocks in their portfolio, thus raising transaction costs and leading to less frequent price movements in the less active ones. The impact of well-documented biases such as overconfidence and the disposition effect on market makers and the concomitant implications for transaction costs would seem to be a valuable topic for research.

\section{REFERENCES}

[1] Tseng, S., and Yang, C. (2011). "The role of information searches in investment choicevariation: Digital information, advice seeking and heuristics", A frican Journal of Business Management 5 (12), 4934-4944.

[2] Tversky, A., \& Kahneman, D. (1986). Rational choice and the framing of decisions. Journal of Sbusiness, 251-278.

[3] Tseng, S.,\& Yang, C. (2011). "Influence of information search on risky investment preferences: Testing a moderating role of income", Proceedings of the 3rd International on Information and Financial Engineering.

DOI Number: https://doi.org/10.30780/IJTRS.V04.I08.004 WWw.ijtrs.com WwW.ijtrs.org 
7 $\mathrm{I}$ S International Journal of Technical Research \& Science

[4] Taylor, S. E. and J. D. Brown. "Illusion and Well-Being: A Social Psychological Perspective on Mental Health.” Psychological Bulletin(1988), 193-210.

[5] Yates, J. F. (1990). Judgment and decision making. Englewood Cliffs, NJ: Prentice Hall. ECB (2003):

[6] Gupta, Chabi. "Payment Banks and Demonetization", International Journal of Technical Research and Science, IJTRS-V1-I9-002, December 2016

[7] Jones, P.and Roelofsma P. (2000) The potential for social contextual and group bias in team decisionmaking: biases, conditions and psychological mechanisms. Ergonomics, vol. 43, no. 8, pp. 1129-1152.

[8] Kahneman, D. and Klein, G. (2010) Strategic decisions: When can you trust your gut? McKinsey Quarterly. http://www.mckinsey.com/insights/strategy/strategic_decisions_when_can_you_trust_your_gut (2013-10-27)

[9] Mulcahy, A. (2010) How we do it: Three executives reflect on strategic decision making. McKinsey Quarterly.

http://www.mckinsey.com/insights/strategy/how_we_do_it_three_executives_reflect_on_strategic_decisio n_making (2013-10-27).

[10] Ukpong, N., Saini, P. and Al Mahmud, A. (2011) Using Availability Heuristics in Game Design to Introduce Children to Energy Sufficient Behaviours at Home. In Human-Computer Interaction INTERACT 2011, ed. Campos, P., Graham, N., Jorge, J., Nunes, N., Palanque, P. and Winckler, M., pp. 661-664. Berlin, Heidelberg: Springer.

[11] Chabi Gupta, P., \& Agarwal, K. Investor Biases in Indian Stock Market. International Journal of Technical Research and Science 1 (5)

[12] Chabi Gupta, P., \& Agarwal, K. Efficient Markets and Financial Bubbles, International Journal of Technical Research and Science 2 (Issue VII)

[13] Baker, H. K., \& Ricciardi, V. (2014). How biases affect investor behaviour.

[14] Menike, L. M. C. S., Dunusinghe, P., \& Ranasinghe, A. (2015). Behavioural Factors Influence on Investment Performance: A Survey of Individual Investors at Colo mbo Stock Exchange. In Proceedings of 10th Annual London Business Research Conference.

[15] Agarwal, A., Verma, A., \& Agarwal, R. K. (2016). Factors influencing the individual investor decision making behaviour in India. Journal of Applied Management and Investments, 5(4), 211-222.

[16] Della Vedova, J., Grant, A. R., \& Westerholm, P. J. (2016). Behavioural Drivers of Momentum Profits for Individual Investors.

[17] Duclos, R. (2015). The psychology of investment behaviour:(De) biasing financial decision-making one graph at a time. Journal of Consumer psychology, 25(2), 317-325.

[18] Liang, H., Yang, C., Zhang, R., \& Cai, C. (2017). Bounded rationality, anchoring-and-adjustment sentiment, and as set pricing. The North American Journal of Economics and Finance, 40, 85-102.

[19] Baker, H. K., Filbeck, G., \& Ricciardi, V. (2017). How Behavioural Biases Affect Finance Professionals.

[20] Chang, C. C., Chao, C. H., \& Yeh, J. H. (2016). The role of buy-side anchoring bias: Evidence from the real estate market. Pacific-Basin Finance Journal, 38, 34-58.

[21] Chabi Gupta, P., \& Agarwal, K. Investor Biases in Indian Stock Market. International Journal of Technical Research and Science 1 (5)

[22] Chabi Gupta, P., \& Agarwal, K. Efficient Markets and Financial Bubbles, International Journal of Technical Research and Science 2 (Issue VII)

[23] Baker, H. K., \& Ricciardi, V. (2014). How biases affect investor behaviour.

[24] Menike, L. M. C. S., Dunusinghe, P., \& Ranasinghe, A. (2015). Behavioural Factors Influence on Investment Performance: A Survey of Individual Investors at Colombo Stock Exchange. In Proceedings of 10th Annual London Business Research Conference.

[25] Agarwal, A., Verma, A., \& Agarwal, R. K. (2016). Factors influencing the individual investor decision making behaviour in India. Journal of Applied Management and Investments, 5(4), 211-222.

[26] Della Vedova, J., Grant, A. R., \& Westerholm, P. J. (2016). Behavioural Drivers of Momentum Profits for Individual Investors.

[27] Duclos, R. (2015). The psychology of investment behaviour:(De) biasing financial decision-making one graph at a time. Journal of Consumer psychology, 25(2), 317-325.

[28] Chabi Gupta, Anchoring effect on portfolio investment decisions - an empirical analysis, International Journal of Scientific \& Engineering Research -IJSER (ISSN 2229-5518, Volume 7 Issue 8, August 2018

[29] Chabi Gupta, Remonetization and India's Journey to a Cashless Economy Through Payments Banks, International Journal of Scientific Development and Research

[30] Chabi Gupta, Portfolio investment decision making and behavioural finance - An empirical analysis, International Journal of Commerce and Management Research, Apr 2017 ISSN: 2455-1627

[31] Chabi Gupta, Portfolio investor personality traits and portfolio investment decisions: An empirical analysis, International Journal of Commerce and Management Research, September 2018 ISSN: 24551627 